\title{
Activated regulatory $T$ cell regulates neural stem cell proliferation in the subventricular zone of normal and ischemic mouse brain through interleukin 10
}

OPEN ACCESS

Edited by:

Francesco Moccia,

University of Pavia, Italy

Reviewed by:

Tsuneya lkezu,

Boston University, USA

Shan Ping Yu,

Emory University, USA

*Correspondence:

Kunlin Jin,

Department of Pharmacology and Neuroscience, University of North

Texas Health Science Center, Fort Worth, TX 76107, USA

kunlin.Jin@unthsc.edu;

Guo-Yuan Yang,

Med-X Research Institute and School of Biomedical Engineering, Shanghai

Jiao Tong University,

1954 Huashan Road,

Shanghai 200030, China

gyyang0626@gmail.com

${ }^{\dagger}$ These authors have contributed equally to this work.

Received: 17 June 2015

Accepted: 28 August 2015 Published: 14 September 2015

Citation:

Wang J, Xie L, Yang C, Ren C, Zhou K, Wang B, Zhang Z, Wang Y, Jin K and Yang G-Y (2015) Activated

regulatory $T$ cell regulates neural

stem cell proliferation in the

subventricular zone of normal and ischemic mouse

brain through interleukin 10.

Front. Cell. Neurosci. 9:361.

doi: 10.3389/fncel.2015.00361

\author{
Jixian Wang ${ }^{1,2,3 \dagger}$, Luokun Xie ${ }^{3 \dagger}$, Chenqi Yang ${ }^{3}$, Changhong Ren ${ }^{3}$, Kaijing Zhou ${ }^{3}$, \\ Brian Wang ${ }^{3}$, Zhijun Zhang ${ }^{2}$, Yongting Wang ${ }^{2}$, Kunlin Jin ${ }^{3 *}$ and Guo-Yuan Yang ${ }^{1,2 *}$ \\ Department of Neurology, Shanghai Ruijin Hospital, Shanghai Jiao Tong University School of Medicine, Shanghai, China, \\ ${ }^{2}$ Med-X Research Institute and School of Biomedical Engineering, Shanghai Jiao Tong University, Shanghai, China, \\ ${ }^{3}$ Department of Pharmacology and Neuroscience, University of North Texas Health Science Center, Fort Worth, TX, USA
}

Recent studies have demonstrated that the depletion of Regulatory $\mathrm{T}$ cells (Tregs) inhibits neural progenitor cell migration after brain ischemia. However, whether Tregs affect neural stem/progenitor cell proliferation is unclear. We explored the effect of Tregs on neurogenesis in the subventricular zone (SVZ) after ischemia. Tregs were isolated and activated in vitro. Adult male C57BL/6 mice underwent 60 min transient middle cerebral artery occlusion $(\mathrm{tMCAO})$. Then Tregs $\left(1 \times 10^{5}\right)$ were injected into the left lateral ventricle (LV) of normal and ischemic mouse brain. Neurogenesis was determined by immunostaining. The mechanism was examined by inhibiting interleukin 10 (IL-10) and transforming growth factor (TGF- $\beta$ ) signaling. We found that the number of $\mathrm{BrdU}^{+}$cells in the SVZ was significantly increased in the activated Tregs-treated mice. Double immunostaining showed that these $\mathrm{BrdU}^{+}$cells expressed Mash1. Blocking $\mathrm{IL}-10$ reduced the number of $\mathrm{Mash}^{+} / \mathrm{BrdU}^{+}$cells, but increased the amount of $\mathrm{GFAP}^{+} / \mathrm{BrdU}^{+}$cells. Here, we conclude that activated Tregs enhanced neural stem cell (NSC) proliferation in the SVZ of normal and ischemic mice; blockage of IL-10 abolished Tregs-mediated NSC proliferation in vivo and in vitro. Our results suggest that activated Tregs promoted NSC proliferation via IL-10, which provides a new therapeutic approach for ischemic stroke.

Keywords: brain ischemia, interleukin 10, neurogenesis, regulatory T cell, subventricular zone

\section{Introduction}

Ischemic stroke leads to irreversible brain injury, because a large number of neurons die during ischemia. This is a major concern for ischemic patients, and remains elusive to be solved. Studies have shown that ischemic stroke could induce neurogenesis in animal and human brains (Hermann et al., 2014; Ruan et al., 2014). Proliferative neural stem cells (NSCs), in response to ischemic injury, would migrate to damaged regions and then differentiate into the mature neuronal cells replacing the damaged neurons (Ruan et al., 2014). This phenomenon fascinated a possibility that neurogenesis could be beneficial to neurological outcomes after ischemia. However, the mechanism underlying stroke-induced neurogenesis is largely unexplored (Jin et al., 2003). 
Immune cells including regulatory $\mathrm{T}$ cells (Tregs) are activated in response to cerebral ischemia. Tregs are considered as the crucial cerebral-protective immunomodulator after brain ischemia (Becker, 2010; Brait et al., 2012; Li et al., 2014), since the removal of Tregs have been observed to aggravate the infarct volume and neurological outcomes by acting on many inflammatory pathways after experimental ischemic stroke (Liesz et al., 2009). Intravenous administration of Tregs protected brain tissue via reducing immune cell infiltration, attenuating cerebral inflammation, and preventing blood barrier disruption following ischemic stroke ( $\mathrm{Li}$ et al., 2013a). It is generally believed that Tregs limit the development of secondary injury by inhibiting inflammation in the brain which could partly reduce neuronal cell death. Also, recent data demonstrated that immune cells, including Tregs, were involved in neurogenesis (Wang and Jin, 2015). Moreover, a recent study showed that the depletion of Tregs suppressed neurogenesis, along with impaired neurological recovery (Saino et al., 2010). However, the relationship between activated Tregs and neurogenesis is still largely unknown.

Interleukin 10 (IL-10) is an anti-inflammatory molecule that maintains the balance between pro- and anti-inflammation. Studies have documented that Tregs predominantly produce IL-10 (Murray, 2006; Saraiva and O'Garra, 2010; Ouyang et al., 2011) which stimulates other Tregs to secrete more IL-10, creating a positive feedback loop (Barrat et al., 2002). This would be important, because IL-10 might play a role in regulating neurogenesis after brain injury. Injecting IL-10 overexpressed NSCs into the experimental autoimmune encephalitis (EAE) mice not only inhibited inflammatory response, but also promoted the differentiation of transplanted NSCs into oligodendrocytes and neurons (Yang et al., 2009).

In the present study, we did not detect endogenous Tregs infiltration into the ischemic brain physiologically. We transplanted exogenous Tregs into the lateral ventricle (LV) as a therapeutic intervention to explore the effect of Tregs on the NSC proliferation in the SVZ. We explore the effect of activated Tregs on the proliferation of NSCs in the subventricular zone (SVZ) of the normal and ischemic mouse brain and to determine the mechanism underlying Tregs-mediated neurogenesis in mice.

\section{Materials and Methods}

\section{Experimental Design}

Animal studies were conducted in accordance with ARRIVE guidelines. Procedure for the use of laboratory animals was approved by the Institutional Animal Care and Use Committee (IACUC) of Shanghai Jiao Tong University, Shanghai, China. In the animal studies, guidelines of the regulation for the administration of affairs concerning experimental animals of China enacted in 1988 were followed. Mice were housed under standard laboratory conditions. Adult male C57BL/6 mice (8-12 weeks) weighing between 25-30 g were used in the experiments. Tregs were isolated from adult C57BL/6 and GFP C57BL/6 mice and then activated in vitro. Mice underwent MCAO at day 0 , followed by Tregs injection into LV at day 1 . BrdU was administrated by intraperitoneal injection daily for 3 days. Finally, mice were sacrificed and brain samples were sectioned for immunostaining (Figure 3A). In the first experiment, mice were randomly divided into three groups ( $n=5$ for normal mice, $n=5-10$ for MCAO mice): (1) Vehicle group, mice injected with PBS; (2) U-Treg group, mice injected with un-stimulated Tregs; and (3) A-Treg group, mice injected with activated Tregs. In the second experiment, mice were randomly divided into three groups ( $n=5$ per group): (1) A-Treg group, mice injected with activated Tregs; (2) A-Treg/Anti-IL-10 group, mice injected with activated Tregs plus IL-10 neutralizing antibody (Ebioscience, Franklin Lakes, NJ, USA); and (3) A-Treg/Anti-transforming growth factor (TGF- $\beta$ ) group, mice injected with activated Tregs plus TGF- $\beta$ neutralizing antibody $(\mathrm{R} \& \mathrm{D}$, Minneapolis, $\mathrm{MN}$, USA). 5-bromodeoxyuridine (BrdU, $50 \mathrm{mg} / \mathrm{kg}$, twice/day) was administrated intraperitoneally after Treg injection for 3 days to label proliferative stem cells in the SVZ of mice. Neurological severity scores (NSS) and evaluated body swing test (EBST) were applied to detect the neurological behavior of MCAO mice. Animals were sacrificed under deep anesthesia 3 days after Tregs transplantation. Infarct volumes were then evaluated by cresyl violet staining, and NSC proliferation was further determined by immunohistochemistry. In in vitro experiment, neurospheres isolated from the brain cortex of 14 days fetal normal mice were randomly divided into three groups ( $n=6$ per group): (1) control group: neurospheres cultured in the normal medium; (2) A-Treg group: neurospheres co-cultured with activated Tregs; and (3) ATreg /anti-IL-10 group: neurospheres co-cultured with activated Tregs plus IL-10 neutralizing antibody. The number and size of neurospheres were statistically analyzed after 3-day co-culturing. In in vivo study, $1 \times 10^{5}$ cells (Sun et al., 2008) in $5 \mu$ l PBS were stereotaxically injected into the left $\mathrm{LV}(\mathrm{AP}=-0.2 \mathrm{~mm}, \mathrm{ML}=-1$ $\mathrm{mm}, \mathrm{DV}=-2.5 \mathrm{~mm})$. The volume of neutralizing antibody IL$10(10 \mu \mathrm{g} / \mathrm{ml})$ and TGF- $\beta(10 \mu \mathrm{g} / \mathrm{ml})$ were $5 \mu \mathrm{l}$. In in vitro study, the concentration of IL-10 neutralizing antibody was $10 \mu \mathrm{g} / \mathrm{ml}$.

\section{Tregs Isolation, Identification and Activation}

Firstly, splenocytes were isolated from adult C57BL/6 and GFP C57BL/6 mice by pressing spleens through $70 \mu \mathrm{m}$ filters (BD Bioscience, San Jose, CA, USA). Secondly, CD4 ${ }^{+}$T cells were sorted using Mouse $\mathrm{CD}^{+}{ }^{+} \mathrm{T}$ cell Pre-enriched Kit (Stemcell, Vancouver, BC, Canada) via magnetic activated cell sorting (MACS). $\mathrm{CD}^{+} / \mathrm{CD} 25^{+}$Tregs were then enriched from $\mathrm{CD} 4{ }^{+}$ $\mathrm{T}$ cells by Flow Activated Cell Sorter (FACS; BD Bioscience) after being labeled with PE anti-mouse CD25 (Biolegend, San Diego, CA, USA). Enrichment of $\mathrm{CD} 4^{+} / \mathrm{CD} 25^{+}$Tregs was further confirmed by Foxp3 staining (Biolegend). These cells were then cultured in the presence of anti-mouse CD28 (2 $\mu \mathrm{g} / \mathrm{ml}$, Ebioscience) and recombinant mouse IL-2 (400 U/ml, Life Technologies, Grand Island, NY, USA) in cell culture plates pre-coated with anti-mouse CD3e $(10 \mu \mathrm{g} / \mathrm{ml}$, Ebioscience, Franklin Lakes, NJ, USA). Three days later, CD44 and CD62L (Biolegend) staining were performed to confirm Treg activation. At the same time, mRNA level of IL-10, TGF- $\beta$ and epstein-barr virus induced gene-3 (ebi3) were evaluated by qRT-PCR.

\section{qRT-PCR}

Total RNAs were extracted using an Arcturus ${ }^{\circledR}$ Picopure ${ }^{\circledR}$ RNA Isolation Kit and were reversely transcribed to cDNAs using a 
SuperScript ${ }^{\circledR}$ First-Strand Synthesis System according to the manufacture's instructions. Real-time PCR was performed using a Power SYBR ${ }^{\circledR}$ Green Master Mix on a 7300 real-time PCR System. Reagents and kits for PCR were all purchased from Life Technologies. Data were analyzed on 7300 system software. Primer sequences (Sigma-Aldrich, St. Louis, MO, USA) for each gene were shown as follows:

\section{IL-10: Forward: 5'AGGCGCTGTCATCGATTTCT3' Reverse: 5'ATGGCCTTGTAGACACCTTGG3' \\ TGF- $\beta$ : Forward: 5'ATGGCGCAAAACAGTCCACA3' Reverse: 5'TGTAACATGCACTGGGATACCA3' \\ ebi3: Forward: 5'CGCTCCCCTGGTTACACTG3' Reverse: 5'CCACGGGATACCGAGAAGC3' \\ $\beta$-actin: Forward: 5'CTGTCGAGTCGCGTCCA3' Reverse: 5'CGCAGCGATATCGTCATCCA3'}

The accession number of target genes is IL-10: NM_010548.2, TGF-beta: NM_011577.1, ebi3: NM_015766.2, Beta-actin: NM_007393.4.

\section{Transient MCAO (tMCAO) in Mice}

Transient MCAO were performed as previously described (Chen et al., 2014). Briefly, mice were anesthetized with 1.5-2\% isoflurane, 30\% oxygen and $70 \%$ nitrous oxide. After exposing internal carotid artery, left external carotid artery and left internal carotid, a 6-0 silicone-coated suture (Doccol, Beijing, BJ, China) was inserted from ECA into ICA to occlude the origin of middle cerebral artery. A successful of occlusion was confirmed by a laser Doppler flowmetry (Perimed AB, Järfälla, Sweden) with a decrease of $80 \%$ compared to the baseline blood flow. Reperfusion was performed by suture withdrawing alone an hour after occlusion. Blood flow returned to the $70 \%$ of baseline was considered successful reperfusion. Sham operated mice underwent the same procedure without inserting the suture.

\section{Immunochemistry}

Mice were euthanatized under deep anesthesia. Brains were removed after $0.9 \%$ sodium chloride and $4 \%$ paraformaldehyde perfusion. After fixation at $4^{\circ} \mathrm{C}$ overnight, brains were embedded in paraffin and were cut into 5 - $\mu \mathrm{m}$ sections. Brain slices were then incubated with antibodies against $\operatorname{BrdU}$ (1:500, mouse, Sigma-Aldrich), DCX (1:200, rabbit, Millipore, Boston, MA, USA), GFAP (1:200, goat, Santa Cruz, Dalas, TX, USA) and Vimentin (1:100, rabbit, Abcam, Cambridge, MA, USA) at $4^{\circ} \mathrm{C}$ overnight, followed by incubation of secondary antibodies (Life Technologies) for $1 \mathrm{~h}$. Negative controls (omit primary antibody) were performed for each staining to avoid bleed through.

For Mash1 (1:100, mouse, BD Bioscience, CA, USA) staining, brain slices were incubated with Biotin/Avidin blocking solution (Vector Lab, Burlingame, CA, USA) for 10 min before serum blocking. After incubating with biotinylated secondary antibody (Vector Lab), Avidin DCS (Vector Lab) was added and incubated with the samples for $10 \mathrm{~min}$. Following steps were the same as above described. Results were observed under an inverted fluorescence microscope (Zeiss, Thornwood, NY, USA).
Photomicrographs were taken to identify and count cells. The positive cells were counted in five immunofluorescent or DAB slices per animal, spaced $100 \mu \mathrm{m}$ apart.

\section{Infarct Volume Measurement}

Mice were sacrificed 3 days after cell injection. Brains were removed and frozen immediately in isopentane. A series of $20-\mu \mathrm{m}$-thick coronal sections from anterior commissure to hippocampus were cut and stained with cresyl violet. Sections were photographed and digitized using Image J software. Infarct volume was then calculated as previously described (Huang et al., 2010).

\section{Neurobehavioral Tests}

Mice underwent modified NSS and EBST tests 1 day after transient middle cerebral artery occlusion (tMCAO) and 1, 2, 3 days after Treg injection. For modified NSS (normal score, 0 ; maximal deficit score, 14), the flexion of forelimb and hindlimb was observed by lifting the tail of the mice $(0-3)$; walk-posture of the mice was observed by being placed on the floor (0-3); the balance ability was evaluated by putting the mice on a beam (0-6); the reflexes absence was detected by pinna reflex and corneal reflex. For EBST test, the mice were held at the tail and raised $10 \mathrm{~cm}$ above the testing surface. The number of wing direction (right or left) was recorded in 20 trials per mouse. The percentage of right biased wing was calculated.

\section{Neurosphere}

NSCs were isolated from E14 C57BL/6 mice and cultured in DMEM/F12 medium including B27 (2\%), bFGF (20 ng/ml), and EGF (20 ng/ml, Life Technologies) as previously described (Tang et al., 2014). Neurospheres from passage 2 were then co-cultured with activated Tregs at a ratio of 2:1.

\section{Statistical Analysis}

Data were presented as mean $\pm \mathrm{SD}$. Data from cell identification, cytokine mRNA levels and the number of $\mathrm{BrdU}^{+}$and $\mathrm{DCX}^{+}$ cell comparison between sham and tMCAO mice were analyzed by student $t$ test. Data among sham, un-activated and activated Tregs were analyzed by one-way analysis of variance (ANOVA), followed by Turkey post hoc comparisons. $p<0.05$ was considered statistically significant.

\section{Results}

\section{Treg Identification and Activation}

CD $4^{+} / \mathrm{CD} 25^{+} \mathrm{T}$ cells are defined as Tregs (Khattri et al., 2003). To quickly obtain pure $\mathrm{CD} 4^{+} / \mathrm{CD} 25^{+}$Tregs, we firstly enriched $\mathrm{CD} 4^{+} \mathrm{T}$ cells using MACS, and then isolated $\mathrm{CD} 4^{+} / \mathrm{CD} 25^{+}$ Tregs by FACS. Compared to the enriched CD ${ }^{+} \mathrm{T}$ cells, the percentage of $\mathrm{CD}^{+} / \mathrm{CD} 25^{+} \mathrm{T}$ cells was higher after MACS and FACS, reaching 97\% (Figure 1A). To further confirm the Treg identity, Foxp3, the master regulator of Tregs (Hori et al., 2003), was detected against sorted $\mathrm{CD} 4^{+} / \mathrm{CD} 25^{+} \mathrm{T}$ cells by flow cytometry analysis (Figure 1A). The result demonstrated that 
A a
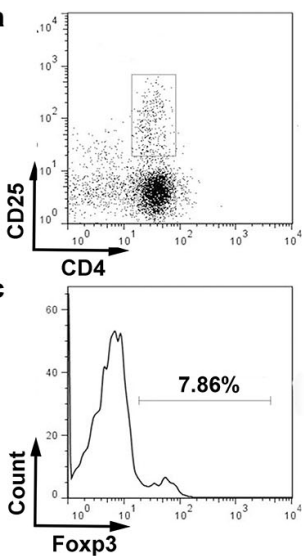

B a
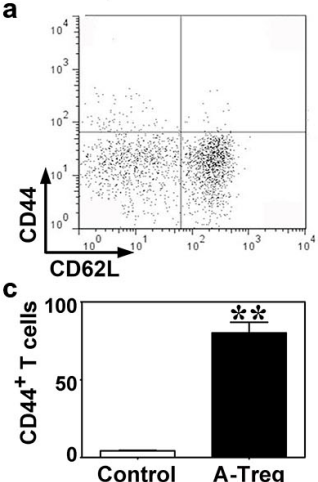

C

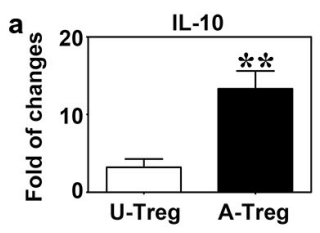

C

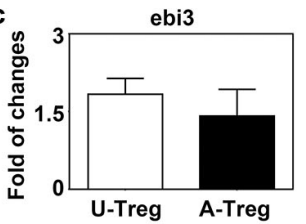

b

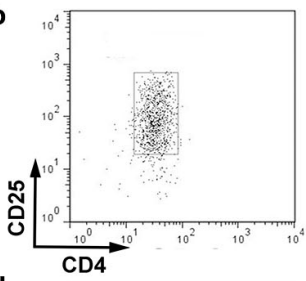

d

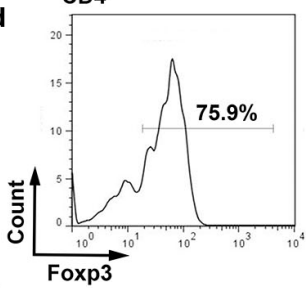

b
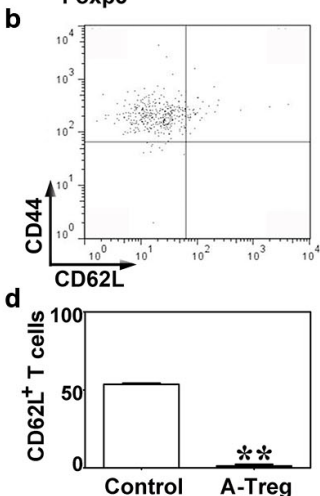

b

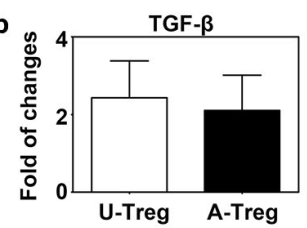

FIGURE 1 | Tregs were identified by CD4/CD25 and activated by CD3e/CD28/IL-2. (A) CD4+/CD25+ Tregs isolated from mouse spleen were analyzed by a flow cytometry sorting (FACS). CD4 ${ }^{+} / \mathrm{CD}^{2} 5^{+}$(b) and Foxp3 (d) were detected after $\mathrm{CD} 4^{+} / \mathrm{CD} 25^{+}$Tregs isolation via magnetic activated cytometry sorting (MACS) and FACS, enriched CD4 ${ }^{+} \mathrm{T}$ cells isolated by MACS being used as the control (a,c). (B) CD44 (a,c) and CD62L (b,d) expression on Tregs after activation. Peripheral blood was used as the control. Data were mean $\pm \mathrm{SD}$, using the student $t$ test. $N=3$ per group. ${ }^{* *} p<0.01$, A-Treg group vs. Control group. (C) IL-10 (a), TGF- $\beta$ (b) and ebi3 (c) mRNA expression of un-stimulated and activated Tregs were quantified by qRT-PCR. Data were mean $\pm \mathrm{SD}$, using the student $t$ test. $N=5-7$ per group. ${ }^{* *} p<$ 0.01, A-Treg group vs. U-Treg group. U-Treg, un-stimulated Tregs; A-Treg, activated Tregs.

Foxp3 expressed in most of $\mathrm{CD}^{+} / \mathrm{CD} 25^{+}$Tregs after MACS and FACS; the percentage was about $69.1 \%$. Since about $20 \%$ of live cells were dead in FACS, the actual percentage of Foxp $3^{+}$ cells would be higher than $69.1 \%$. These results suggested that

most of cells we isolated from spleen were $\mathrm{CD} 4^{+} / \mathrm{CD} 25^{+} / \mathrm{Foxp}^{+}$ Tregs.

To activate Tregs, CD3e Ab, CD28 Ab, and IL-2 were administered to stimulate $\mathrm{CD} 4^{+} / \mathrm{CD} 25^{+}$Tregs for 3 days. CD 44 and CD62L expressions were measured by flow cytometry. Student $t$ test was used to analyze the difference between the control and activated Tregs groups. The results demonstrated that the Tregs significantly up-regulated CD44 (80.0\%) and down-regulated CD62L (1.2\%) after stimulation (Figure 1B), indicating Tregs were indeed activated. On the contrary, Tregs freshly isolated from blood expressed CD44 at a low level (4.4\%) and CD62L at high level (53.6\%; Figure 1B). IL-10, TGF- $\beta$ and ebi3 mRNA levels were examined by qRT-PCR to explore cytokine production in Tregs. Using student $t$ test, we demonstrated that IL-10 was markedly increased in activated Tregs compared to un-stimulated Tregs while TGF- $\beta$ and ebi3 were not altered (Figure 1C). Thus, activated Tregs expressed high level of IL-10, which might play an important role in the function of activated Tregs.

\section{Activated Tregs Promoted NSC Proliferation in the Mouse Brain}

PBS, un-stimulated and activated Tregs were injected into the LV of naive mice to explore the effect of Tregs on NSC proliferation. Three days after injection, using the one-way ANOVA with Turkey post hoc comparisons, we found that $\mathrm{BrdU}^{+}$cells were significantly increased in mice receiving activated Tregs, while there was no change in mice receiving PBS or un-stimulated Tregs (Figure 2A), which suggested that activated Tregs could promote NSC proliferation in the SVZ of naïve mice.

NSCs in the SVZ consist of four cell types including A, B, $\mathrm{C}$ and E. To determine which types of NSCs were changed, we chose four commonly used molecular markers of the four cell types to double-stain with BrdU. DCX, GFAP, Mash1 and Vimentin were utilized as the marker to distinguish cell type A, $\mathrm{B}, \mathrm{C}$ and $\mathrm{E}$, respectively. As shown in the immunofluorescence staining, DCX, GFAP and Vimentin were expressed in cytoplasm while Mash1 was expressed in the cell nucleus (Figure 2B).

By analyzing the percentage of $\mathrm{DCX}^{+} / \mathrm{BrdU}^{+}$, $\mathrm{GFAP}^{+} / \mathrm{BrdU}^{+}, \mathrm{Mash}^{+} / \mathrm{BrdU}^{+}$and Vimentin $^{+} / \mathrm{BrdU}^{+}$ cells in $\mathrm{BrdU}^{+}$cells (Figure 2C), we verified that most $\mathrm{BrdU}^{+}$ cells were $\mathrm{DCX}^{+}$cells (48.3-55.3\%), followed by $\mathrm{GFAP}^{+} / \mathrm{BrdU}^{+}$ cells (22.5-32.1\%), and then Vimentin ${ }^{+} / \mathrm{BrdU}^{+}$cells (0.4-1.1\%). Using the one-way ANOVA with Turkey post hoc comparisons, we further found that $\mathrm{Mash}^{+} / \mathrm{BrdU}^{+}$cells were significantly increased in mice receiving activated Tregs (41.0\%) compared to mice receiving PBS (31.1\%) or un-stimulated Tregs $(28.8 \%)$. Therefore, we confirmed that activated Tregs mainly affected Mash $1^{+} / \mathrm{BrdU}^{+}$cells (C cell type), while having no impact on $\mathrm{A}$, $\mathrm{C}$ or $\mathrm{E}$ cell types under normal conditions.

\section{Activated Tregs Promoted NSC Proliferation Following MCAO}

Nest, the potential connection between Treg injection and neurogenesis development in cerebral ischemia was evaluated next. We performed MCAO to explore the Tregs on NSC proliferation in the ipsilateral SVZ. Using the student $t$ test, 


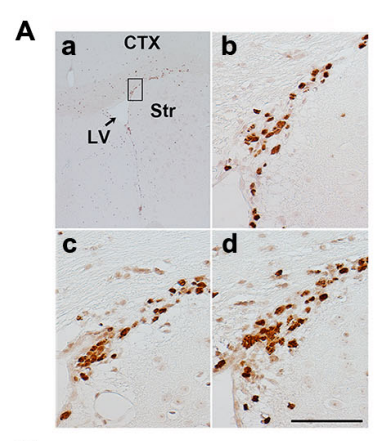

B
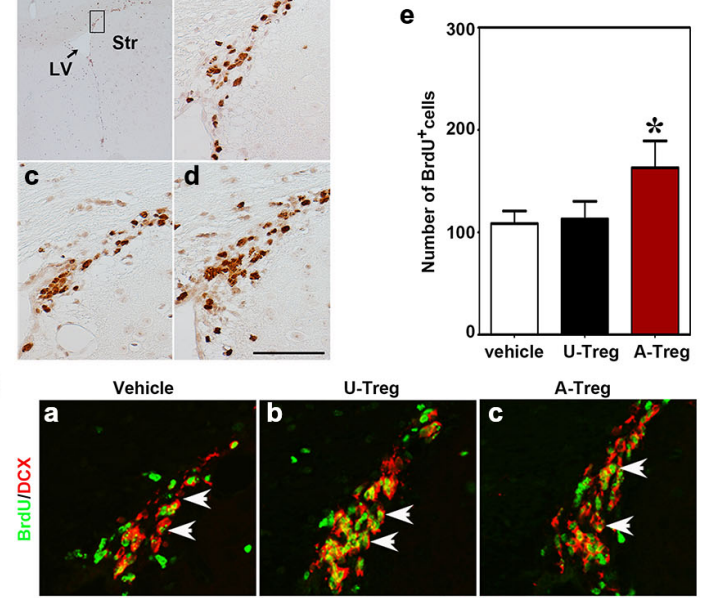

$$
\text { U-Treg }
$$
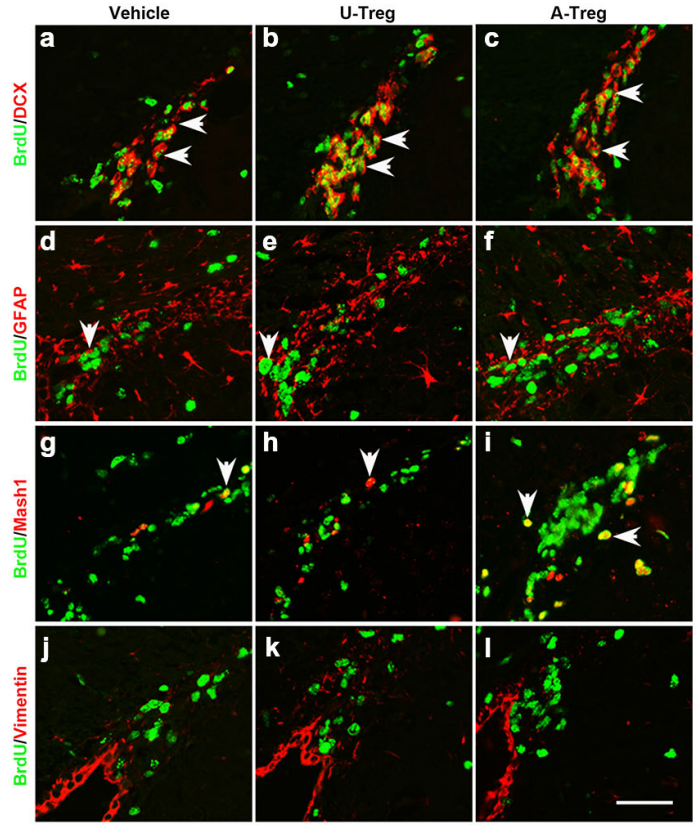

C

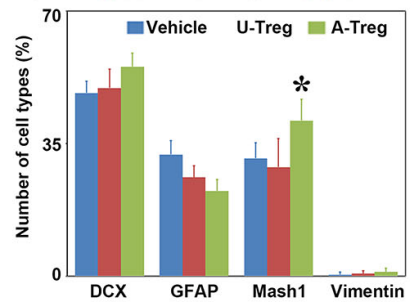

FIGURE 2 | Activated Tregs promoted NSC proliferation in the SVZ of naïve mice. (A) BrdU DAB staining was performed in the Vehicle (b), U-Treg (c) and A-Treg (d) groups of normal mouse. Scale bar $=50 \mu \mathrm{m}$. The number of BrdU positive cells was counted in the anterior of SVZ (in the black box of a). Bar graph (e) semi-quantified the number of $\mathrm{BrdU}^{+}$cell in the Vehicle, $\mathrm{U}$-Treg and A-Treg groups of naïve mice. Scale bar $=100 \mu \mathrm{m}$. Data were mean $\pm \mathrm{SD}$, using the one-way ANOVA followed by Turkey post hoc comparisons. $N=5$ per group. ${ }^{*} p<0.05$, A-Treg vs. U-Treg and Vehicle groups. (B) Four types of neural stem cell in (NSC) the mouse SVZ were identified by immunofluorescence following PBS, un-stimulated and activated Tregs injecting into lateral ventricle (LV). BrdU double stained with DCX (a-c), GFAP (d-f), Mash1 (g-i) and Vimentin (j-l) were presented respectively in Vehicle, U-Treg and A-Treg groups. The arrow indicated the double-stained positive cells. Scale bar $=50 \mu \mathrm{m}$. (C) The percentage of the four cell types in $\mathrm{BrdU}^{+}$cells were quantified in Vehicle, U-Treg and A-Treg groups, separately. Data were mean $\pm \mathrm{SD}$, using the one-way ANOVA followed by Turkey post hoc comparisons. $N=5$ per group. ${ }^{*} p<0.05$, A-Treg group vs. Vehicle and $U$-Treg groups. Vehicle, PBS injection; U-Treg, un-stimulated Tregs injection; A-Treg, activated Tregs injection.
A

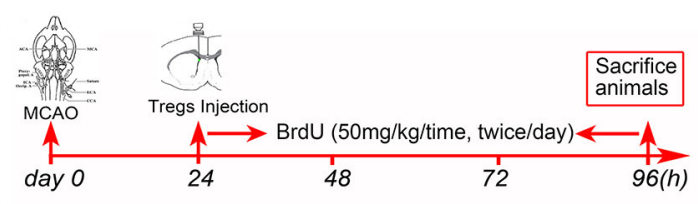

B
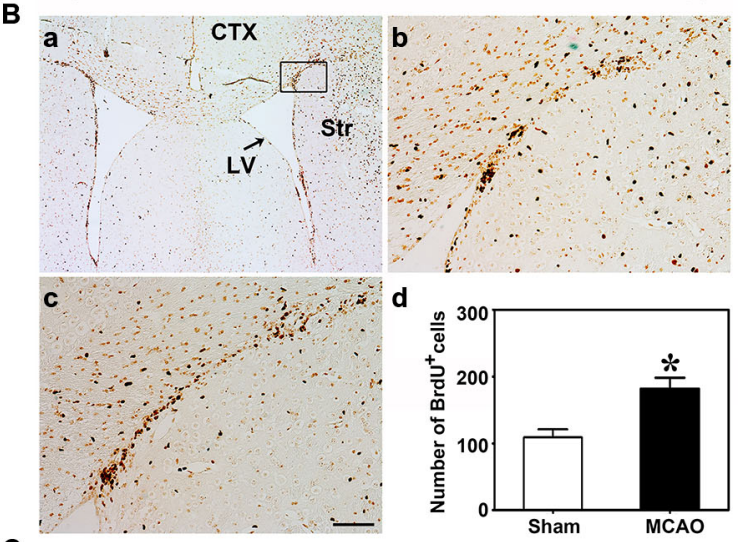

C
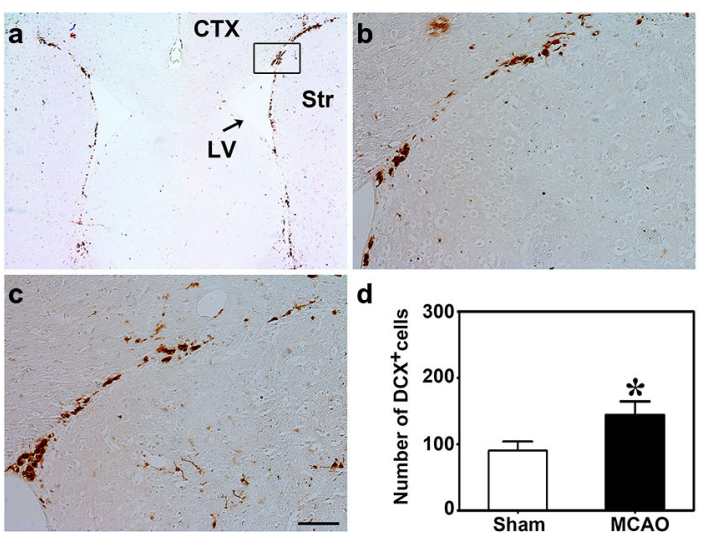

FIGURE 3 | Brain ischemia induced NSC proliferation. (A) Flow chart of the experiment. Mice underwent MCAO at day 0 , followed by Tregs transcranial injection into LV at day 1. Then BrdU was administrated by intraperitoneal injection for 3 days. Finally, mice were sacrificed for immunostaining. (B) Photomicrographs showed BrdU ${ }^{+}$cells in the ipsilateral SVZ in the sham (b) and the MCAO (c) group. The black box (a) represented the region we are interested and $\mathrm{BrdU}^{+}$cell counted. (d) Bar graph demonstrated the number of $\mathrm{BrdU}^{+}$cells in the sham and the MCAO groups. Data were mean $\pm \mathrm{SD}$, using the student $t$ test. Scale bar $=100 \mu \mathrm{m} . N=5$ per group. ${ }^{*} p<0.05, \mathrm{MCAO}$ group vs. Sham group. (C) $\mathrm{DCX}{ }^{+}$cells were detected by immunostaining in the sham (b) and MCAO (c) groups. The selected area where we counted $\mathrm{DCX}^{+}$cells was shown in the black box (a). Comparison of $\mathrm{DCX}^{+}$cells number between sham and MCAO group (d). Scale bar $=100 \mu \mathrm{m}$. Data were mean $\pm \mathrm{SD}$, using the student $t$ test. $N=5$ per group. ${ }^{*} p<0.05$, MCAO vs. sham and U-Treg groups.

we demonstrated that $\mathrm{BrdU}^{+}$(Figure 3B) and $\mathrm{DCX}^{+}$cells (Figure 3C) were robustly increased in mice after MCAO compared to the sham mice. This indicated that ischemia could induce NSC proliferation. Then we injected PBS, unstimulated Tregs and activated Tregs into the LV of ipsilateral hemisphere of mice following MCAO. Using the one-way ANOVA with Turkey post hoc comparisons, we found that the number of $\mathrm{BrdU}^{+}$cells was greatly increased in the mice receiving activated Tregs compared to those receiving PBS or 
un-activated Tregs (Figures 4A,B), suggesting that activated Tregs could also promote ischemia-induced NSC proliferation. We further demonstrated that activated Tregs increased the number of $\mathrm{Mash}^{+} / \mathrm{BrdU}^{+}$cells while decreased $\mathrm{GFAP}^{+} / \mathrm{BrdU}^{+}$ cells (Figures $4 \mathrm{~B}, \mathrm{C}$ ). These results indicated that activated Tregs could act on the B and $\mathrm{C}$ cell types after brain ischemia.

\section{Transplantation of Activated Tregs did not Improve Stroke Outcomes in Mice}

To assess stroke outcomes in tMCAO mice treated with PBS, un-stimulated Tregs and activated Tregs, we performed cresyl violet staining to measure the infarct volume (Figures 5A,B) and neurobehavioral test (Figures 5C,D) to observe the neurological deficits. Data were analyzed by one-way ANOVA with Turkey post hoc comparisons in Vehicle, U-Treg and A-Treg groups. We did not find the difference of infarct volume among three groups. Similar to the changes of infarct volume, there was no difference of NSS and EBST tests among three groups.

\section{Tregs were Found in the Lateral Ventricle and Adjacent Brain Parenchyma after Injection}

To determine the location of Tregs after injection, GFP-Tregs were isolated, activated and injected into the LV as previously described. Three days after injection, mice brains were removed and cut. The brain slices were then stained with DAPI and observed under a fluorescence microscope. GFP-Tregs were found in the brains of A-Treg and U-Treg groups, but not in PBS group. Additionally, GFP-Tregs were found to be located in LV and adjacent brain parenchyma (Figure 6).

\section{Activated Tregs Activated NSCs via IL-10 In Vitro and In Vitro}

Previous studies showed that IL-10 and TGF- $\beta$ were closely related to stimulation of neurogenesis locally (Liu et al., 2009; Kohman and Rhodes, 2013; Casari et al., 2014). Therefore, we speculated that activated Tregs promote NSC proliferation through secreting cytokines. We injected activated Tregs plus IL-10 or TGF- $\beta$ neutralizing antibodies into the LV of naive mice to detect whether blocking either IL-10 or TGF- $\beta$ would block the function of activated Tregs (Grossman et al., 2004; Pineda et al., 2013). Data were analyzed by one-way ANOVA with Turkey post hoc comparisons in A-Treg, A-Treg/Anti-IL10 , and A-Treg/Anti-TGF- $\beta$ groups. The results confirmed that the administration of activated Tregs plus IL-10 Ab decreased the proportion of $\mathrm{Mash}^{+} / \mathrm{BrdU}^{+}$cells in total pool of $\mathrm{BrdU}^{+}$ cells, and meanwhile conversely increased the percentage of $\mathrm{GFAP}^{+} / \mathrm{BrdU}^{+}$cells (Figure 7A). Blocking TGF- $\beta$ did not alter the effect of activated Tregs on NSC proliferation (Figure 7B). The results suggested that IL-10 played a key role in the enhancement of NSC proliferation by activated Tregs.

IL-10 neutralizing antibody was added into the activated Tregs and neurosphere co-culture to verify the role of IL-10 in vitro. Data were analyzed by one-way ANOVA with Turkey post hoc comparisons in control, A-Treg, and A-Treg/Anti-IL10-groups. The results suggested that activated Tregs increased the number of neurospheres $(20-50 \mu \mathrm{m})$ compared to those

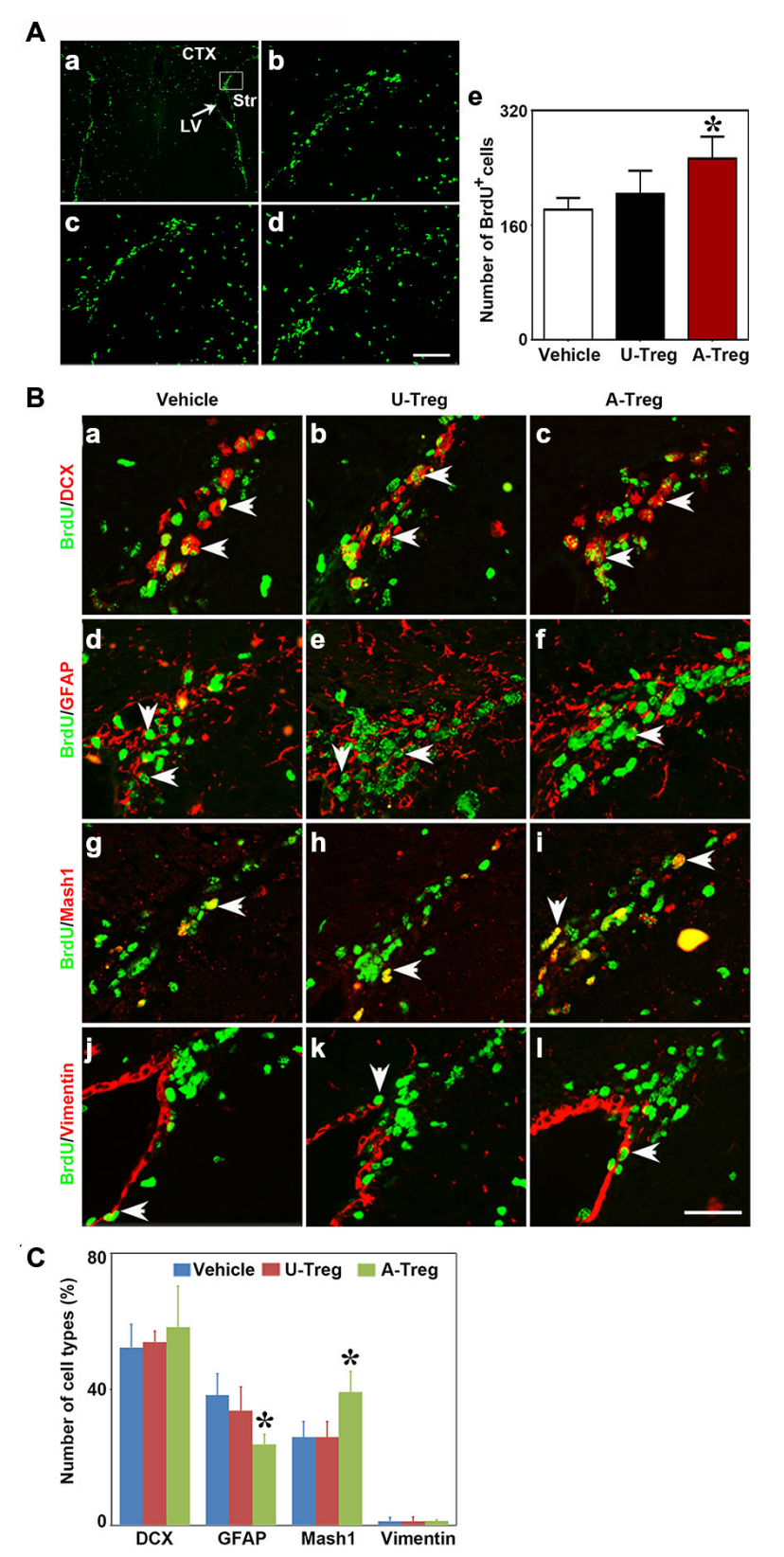

FIGURE 4 | Activated Tregs promoted NSC proliferation in the SVZ of mice following middle cerebral artery occlusion (MCAO). (A)

Photograph of immunofluorescence staining showed BrdU ${ }^{+}$cells in the SVZ of MCAO mice treated with PBS (b), un-stimulated Tregs (c) and activated Tregs (d) injection into the left LV. The black box (a) showed the area we counted the cells. BrdU ${ }^{+}$cell number was quantified in the three groups (e). Scale bar $=100 \mu \mathrm{m}$. Data were presented as mean $\pm \mathrm{SD}$, using the one-way ANOVA followed by Turkey post hoc comparisons. $N=5-10$ per group. ${ }^{*} p<$ 0.05, A-Treg group vs. U-Treg and Vehicle groups. (B) Double-labeled fluorescence staining detected the expression of $\mathrm{BrdU}^{+} / \mathrm{DCX}^{+}(\mathbf{a}-\mathbf{c})$, $\mathrm{BrdU}^{+} / \mathrm{GFAP}^{+} \mathrm{B}(\mathbf{d}-\mathbf{f}), \mathrm{BrdU}^{+} / \mathrm{Mash}^{+} \mathrm{C}(\mathbf{g}-\mathbf{i})$ and BrdU + Nimentin ${ }^{+} \mathbf{( j - l )}$ in SVZ of mice after MCAO in Vehicle, U-Treg and A-Treg groups. The arrow indicated the positive cells. Scale bar $=50 \mu \mathrm{m}$. (C) Statistical analysis of the percentage of $\mathrm{A}, \mathrm{B}, \mathrm{C}$ and $\mathrm{E}$ type in $\mathrm{BrdU}^{+}$cells after PBS, Vehicle, un-stimulated and activated Tregs (d) injection. Data were mean \pm SD, using the one-way ANOVA followed by Turkey post hoc comparisons. $N=5$ per group. ${ }^{*} p<0.05$, A-Treg vs. Vehicle and U-Treg groups. 


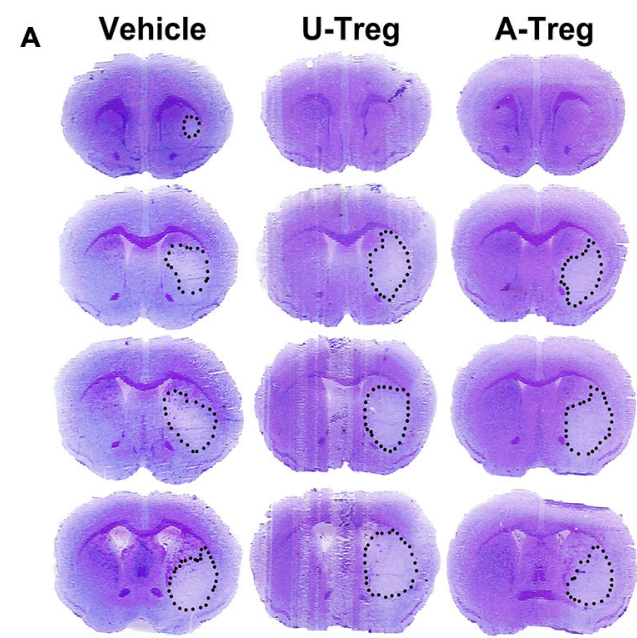

B

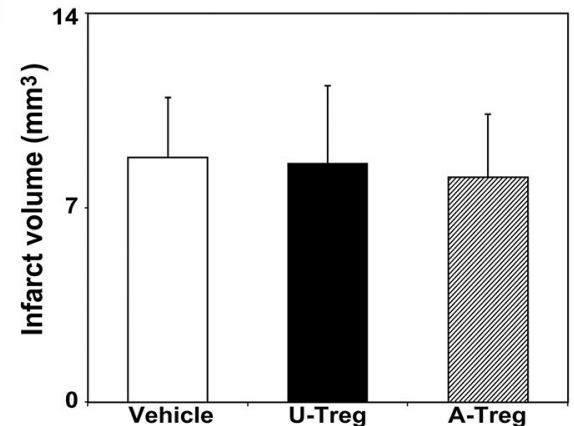

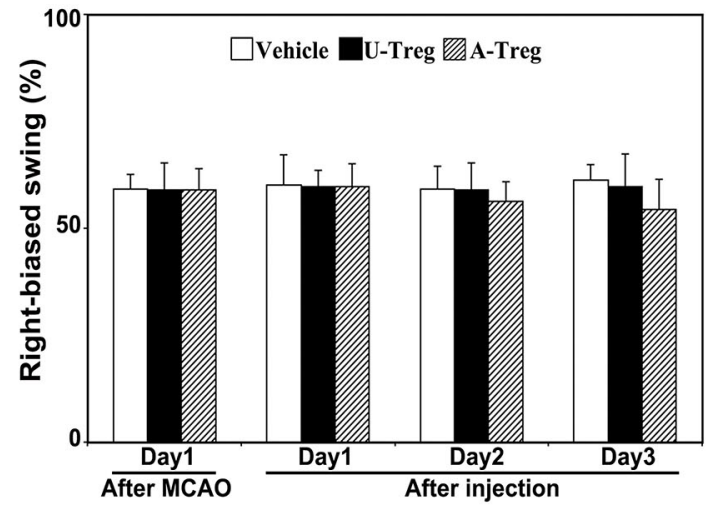

D

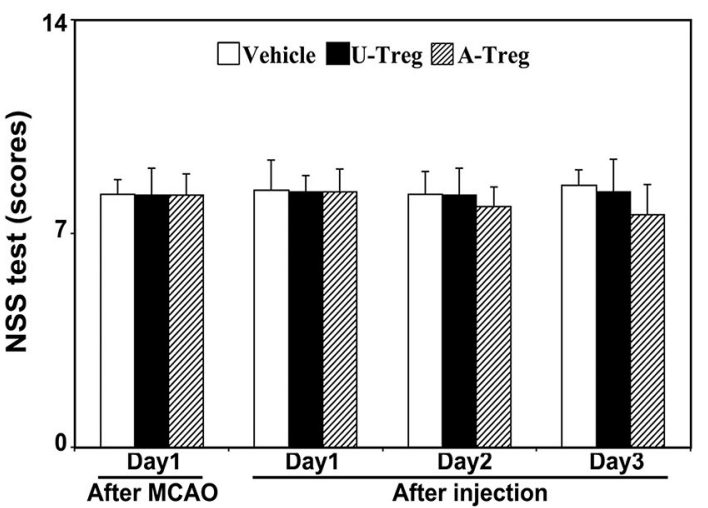

FIGURE 5 | Activated Tregs did not affect stroke outcomes in mice. (A) Cresyl violet staining of mice brain sections showed the infarct volume after 3 days treatments following MCAO. The outlines indicated the infarct area. (B) Quantification of the infarct volumes. (C) Bar graph showed the mNSS test to evaluate neurological deficiency after 3 days treatments in MCAO mice. (D) Bar graph represented the elevated body swing test scores to measure the percentage of turns to the impaired side. Data were mean $\pm \mathrm{SD}$, using the one-way ANOVA followed by Turkey post hoc comparisons. $N=7-8$ per group.

in the normal medium (Figures $\mathbf{8 A , B}$ ). In contrast, the IL10 neutralizing antibody decreased neurosphere size compared to the neurospheres co-cultured with activated Tregs. Taken together, these data indicated that activated Tregs promoted NSC proliferation via IL-10.

\section{Discussion}

In this study, we confirmed that: (1) Tregs could be isolated from the spleen and activated by CD3e/CD28/IL-2 in vitro; (2) Activated Tregs promoted NSC proliferation in the ipsilateral SVZ in both normal and MCAO mice; (3) the main target stem cells influenced by activated Tregs were type C cells; and (4) the regulation of activated Tregs on NSC proliferation was through IL-10 signaling.

Numerous studies demonstrated that Tregs could migrate to the injured region after cerebral ischemia, which played an important role for immunomodulation (Kleinschnitz et al., 2013; Brea et al., 2014; Chu et al., 2014). Furthermore, intravenously injecting Tregs showed neuroprotection via suppressing immune responses (Li et al., 2013a,b). However, these studies did not detect Tregs infiltration in the LV.
The purpose of our study was to promote neurogenesis. We injected Tregs into the LV because NSCs located in the SVZ, which might directly stimulate neurogenesis at that region.

Tregs need to be activated to fully exert their immunosuppressive function. The activated Tregs express CD44 ${ }^{\text {high }}$ CD62 $\mathrm{L}^{\text {low }}$ while the un-stimulated Tregs, also called natural Tregs, express CD44 ${ }^{\text {low }}$ CD62L ${ }^{\text {high }}$ (Liston and Gray, 2014). In our experiment, CD3e/CD28/IL-2 were used to stimulate isolated Tregs. These Tregs expressed CD $44^{\text {high }}$ and CD62 $\mathrm{L}^{\text {low }}$ following 3 days' cytokine stimulation. After Treg injection, NSC proliferation was only detected in activated Tregs treated mice, indicating that Tregs are required to be activated and this is an important step to affect the NSC proliferation.

The link between inflammation and neurogenesis has recently garnered attention, with an emphasis on the impact of immune cells on neurogenesis (Ekdahl et al., 2009; Brait et al., 2012; Kohman and Rhodes, 2013). For instance, hippocampal neurogenesis was significantly impaired in $\mathrm{CD}^{+} \mathrm{T}$ cell immunodeficient mice and an enriched environment did not reduce the damage (Ziv et al., 2006). Similarly, hippocampal neurogenesis was reduced after systemic depletion of $\mathrm{CD} 4^{+} \mathrm{T}$ 


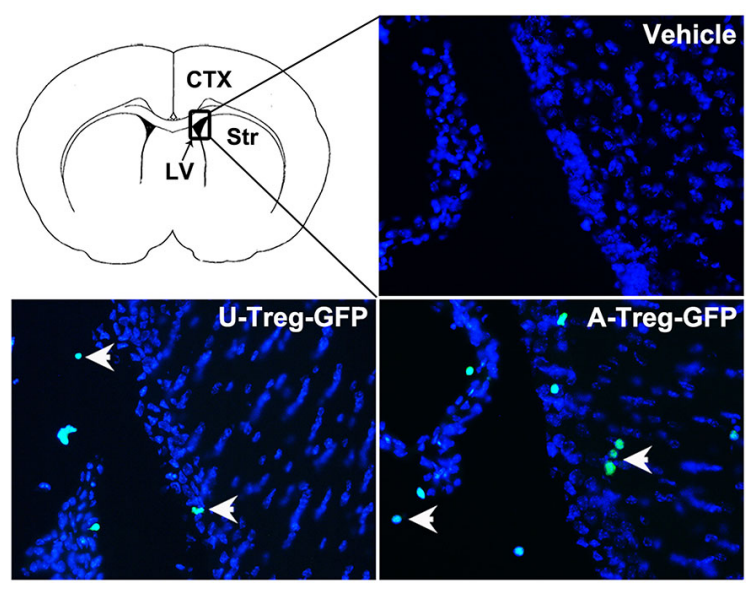

FIGURE 6 | Tregs in the LV and adjacent brain parenchyma. GFP-Tregs stained with DAPI were presented respectively in vehicle, U-Treg and A-Treg groups. Picture at the upper left showed the diagram of coronal brain section. The black box represents the region we observed. The arrows showed U-Treg-GFP and A-Treg-GFP cells.

cells and the mouse reversal learning ability tested in the Morris water maze was greatly impaired (Wolf et al., 2009). In this experiment, the effect of $\mathrm{CD}^{+} \mathrm{T}$ and $\mathrm{B}$ cells on neurogenesis was not found. Current study indicated that the hippocampal stem cell proliferation in the heterogeneous stock mice was correlated with the ratio of $\mathrm{CD} 4^{+} / \mathrm{CD} 8^{+} \mathrm{T}$ cells. Knockout and depleting $\mathrm{T}$ cells revealed that $\mathrm{T}$ cells could influence neurogenesis (Huang et al., 2010). However, the mechanism of $\mathrm{CD} 4^{+} \mathrm{T}$ cell-mediated hippocampal neurogenesis remains unknown. The effect of $\mathrm{CD}^{+} \mathrm{T}$ cell on neurogenesis could be due to a subtype of $\mathrm{CD}^{+}{ }^{+} \mathrm{T}$ cell, or cytokine production. Our results demonstrated that activated Tregs, a subtype of $\mathrm{CD}^{+} \mathrm{T}$ cell, promote NSC proliferation, providing a possibility to elucidate the function of $\mathrm{CD} 4^{+} \mathrm{T}$ cells on neurogenesis.

In our study, activated Tregs administration did not reduce infarct volume or improve neurobehavior in the early stage of ischemia. Exploring the effect of activate Tregs on improvement of neurological outcomes is interesting and important; however, further long term experiments are needed to prove the function of Tregs on regeneration. The short term effect of Tregs on neurogenesis is not sufficient to improve the outcomes of MCAO mice. Perhaps Tregs-induced neurogenesis takes time and long term observation is needed.

Immune cell-induced neurogenesis could be caused by secreted cytokines. For example, $\mathrm{CD}^{+}{ }^{+} \mathrm{T}$ cell depletion not only reduced $\mathrm{Ki}_{67}{ }^{+}$and $\mathrm{BrdU}^{+}$cells in the dentate gyrus, but also decreased brain derived neurotrophic (BDNF) production (Wolf et al., 2009). Because cytokines such as IL-4 derived from $\mathrm{CD}^{+} \mathrm{T}$ cells could promote resident microglia or neurons in dentate gyrus to secret BDNF, which could promote focal neurogenesis (Schwartz and Shechter, 2010). Intravenous injection of homogeneous Th17 enhanced the hippocampal stem cell proliferation in CD4 $\mathrm{T}$ immunodeficient mice, suggesting this effect was not due to the direct contact between NSCs and the infiltrated Th17 cells. Further study indicated that Th17-derived

\section{A}
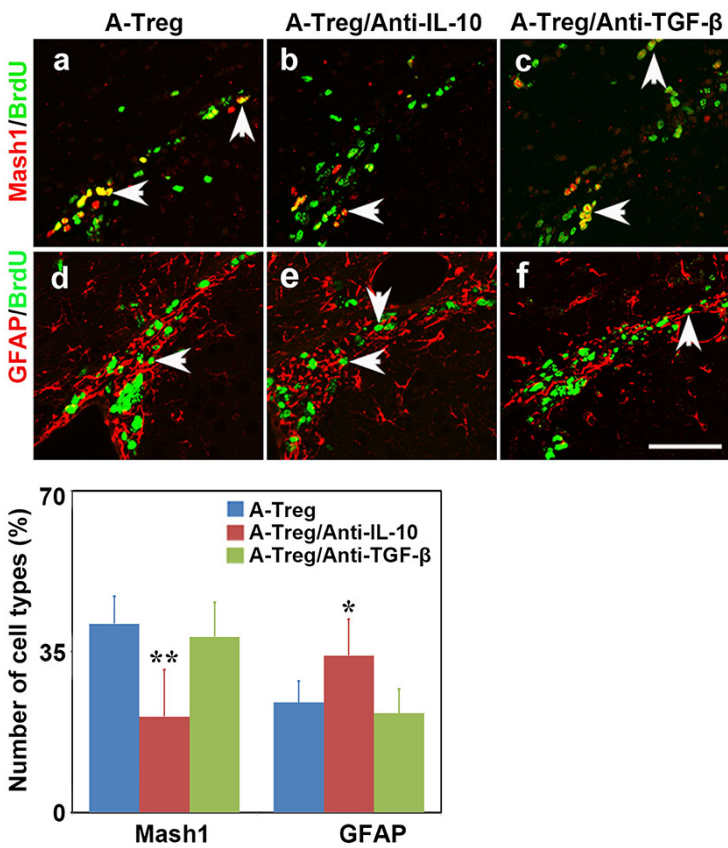

FIGURE 7 | Activated Tregs promoted NSC proliferation through IL-10 in vivo. (A) Type $\mathrm{C}$ and type $\mathrm{B}$ cells in the mouse SVZ were identified by immunofluorescence following activated Tregs, activated Tregs plus IL-10 or TGF- $\beta$ neutralizing antibodies injecting into LV of naiive mice. BrdU double stained with Mash1 $(\mathbf{a}-\mathbf{c})$ and GFAP $(\mathbf{d}-\mathbf{f})$ were presented respectively in A-Treg, A-Treg/anti-IL-10 and A-Treg /anti-TGF- $\beta$ group. Scale bar $=50 \mu \mathrm{m}$. (B) Bar graph showed the percentage of $\mathrm{C}$ and $\mathrm{B}$ types in $\mathrm{BrdU}^{+}$cells after in A-Treg, A-Treg/anti-IL-10 and A-Treg /anti-TGF- $\beta$ group. Data were mean \pm $\mathrm{SD}$, using the one-way ANOVA followed by Turkey post hoc comparisons. $N=$ 5 per group. ${ }^{*} p<0.05,{ }^{* *} p<0.01$, A-Tregs vs. A-Treg/Anti-IL-10 and A-Treg/Anti-TGF- $\beta$ group.

cytokines functioned on hippocampal precursor cells (Niebling et al., 2014). We demonstrated that Tregs could express high level of IL-10 but not TGF- $\beta$ and IL35 after activation. In addition, neutralizing IL-10 decreased the number of $\mathrm{BrdU}^{+} / \mathrm{Mash}^{+}$ cells, indicating that activated Tregs enhanced NSC proliferation via IL-10 in vivo. The in vitro experiment also confirmed the role of IL-10 in Treg-mediated neurosphere proliferation. Therefore, we believe that IL-10 is a key factor in activated Treg regulation on NSC proliferation.

Our results demonstrated that activated Tregs have a unique feature for stimulating stem cell proliferation. We did not detect stem cell proliferation in the un-activated Tregs or PBS injected mice, suggesting activated Tregs is a main stimulator. Although Bregs secret IL-10, whether Bregs involve in IL-10 induced stem cell proliferation needs to be further studied. Tregs play numerous roles in diseases especially in inflammation. Tregs could protect ischemic brain injury through many different ways, such as reducing $\mathrm{BBB}$ disruption and inhibiting inflammatory response (Li et al., 2013a). Studies also indicated that Tregs played controversial roles in ischemic stroke; however, this effect mostly related to ischemia induced inflammatory response. Since Tregs stimulating stem cell 


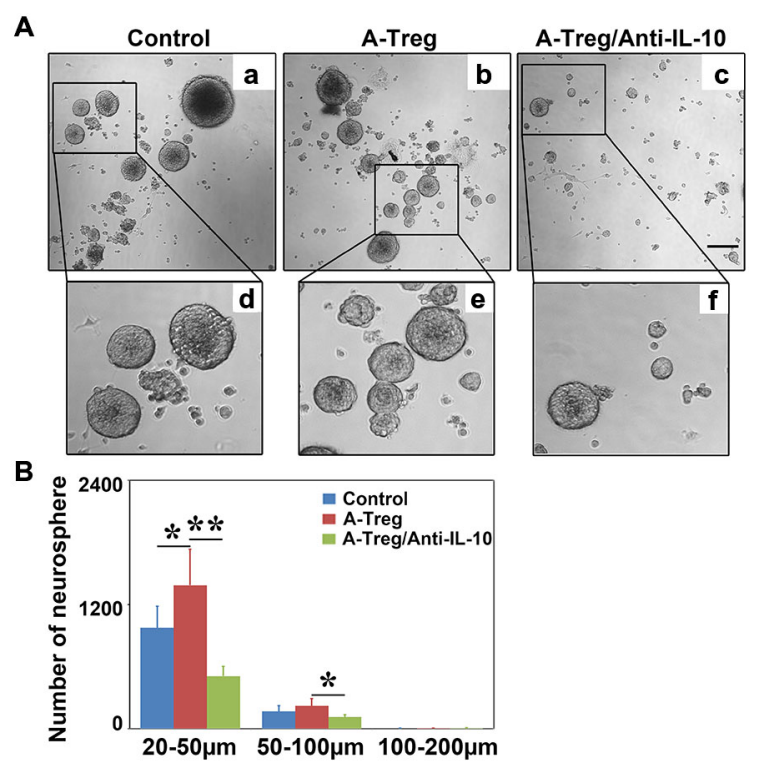

FIGURE 8 | Activated Tregs enhanced neurosphere proliferation via IL-10 in vitro. (A) Neural spheres were observed after 3 days treatment under inverted phase contrast microscope. a-c respectively showed the growing states of neural sphere cultured in normal medium, co-cultured with activated Tregs and activated Tregs plus anti-IL-10. d-f represented the magnification of the black box in $\mathbf{a}-\mathbf{c}$. (B) The size and number of neural sphere treated with activated Tregs and activated Tregs A-Treg plus anti-IL-10 was quantified. Data were mean $\pm \mathrm{SD}$, using the one-way ANOVA followed by Turkey post hoc comparisons. $N=6$ per group. ${ }^{*} p<0.05,{ }^{* *} p<0.01$, A-Treg group vs. A-Treg/Anti-IL-10 and control group.

proliferation has not been studied yet, we explore this question in this study.

Tregs played an import part in the pathophysiological process during ischemic stroke. Tregs could migrate into the ischemic region and regulate immune responses (Stubbe et al., 2013). Studies showed that Tregs involved in the modulation of neurogenesis. For instance, Tregs removal reduced the number of Nestin ${ }^{+}$cells after ischemic stroke (Saino et al., 2010). Emerging studies indicated that immune cells were capable to promote neurogenesis, mainly via the secretion of soluble factors (Kokaia et al., 2012). Recent studies established the role of IL-10 in neurogenesis. IL-10 overexpression in the hippocampal neurons increased $\mathrm{DCX}^{+}$and $\mathrm{BrdU}^{+} / \mathrm{NeuN}^{+}$ cells in the subgranular zone of APP/PS1 mice. Nestin, Sox1, Sox2, Musashi, and Mash1 (pro-neural gene markers) were upregulated but Numb, DCX and TUBB3 were down-regulated after IL-10 infusion (Perez-Asensio et al., 2013). This result suggested that IL-10 has a growth factor function. It maintains the un-differentiated status of progenitor cells and modulates neurogenesis. Since IL-10 receptor (IL-10R) was expressed on the NSCs (Perez-Asensio et al., 2013); IL-10 has been shown to modulate neurogenesis through interacting with IL-10R and thus activating downstream signaling pathway ERK and STAT3 regulated by IL-10 (Pereira et al., 2015). Furthermore, IL10 infusion into the $\mathrm{LV}$ of mouse increased the number of $\mathrm{Mash}^{+}$cells (type C) and decreased the number of $\mathrm{DCX}^{+}$cells (type A) in SVZ (Perez-Asensio et al., 2013). In our study, it was noted that type $\mathrm{C}$ cells were increased after injection of activated Tregs. This may be due to: (1) activated Tregs mainly secret IL-10; (2) IL-10 receptor is up-regulated in activating proliferating cells such as type C cells. Application of IL-10 $\mathrm{KO}$ mice is the best way to investigate the function of IL10 in activated Tregs-mediated-NSC proliferation; however, Currently IL-10 KO mice are unavailable in China. Developing IL-10 KO mice is time-consuming. In our experiment, IL-10 neutralizing antibody was added to inhibit the function of IL-10. We showed that IL-10 inhibition blocked the effect of activated Tregs on NSC proliferation, which could partially explain the critical role of IL-10 in NSC proliferation induced by activated Tregs.

Saino's report demonstrated that inhibiting endogenous Tregs reduced Nestin $^{+}$cells after ischemia, suggesting that Tregs play a role on maintaining and promoting neurogenesis during ischemic brain injury. In our experiment, we further demonstrated exogenous administration of Tregs could increase $\mathrm{BrdU}^{+}$cells in the SVZ, suggesting that both endogenous and exogenous Tregs could promote neurogenesis. Therefore, both enhancing endogenous Tregs and injecting exogenous Tregs can be used for stroke therapy. Previous studies demonstrated that IL-10 increased after cerebral ischemia, and IL-10 overexpression could promote neurogenesis (Kiyota et al., 2012; Tobin et al., 2014). Yet no evidence suggests that anti-IL-10 could diminish neurogenesis. Nevertheless, IL-10 is related to neurogenesis in the brain. Increasing IL-10 by activated Tregs is more effective than administrating IL-10 protein itself, since the half-life of IL10 protein is short.

TGF- $\beta$ is known for its negatively modulating neurogenesis (Buckwalter et al., 2006). For example, blocking TGF- $\beta$ increases $\mathrm{BrdU}^{+}$and $\mathrm{BrdU}^{+} / \mathrm{CD} 24^{-} / \mathrm{Glastin}^{+}$cells in aged and irradiated mice, but does not change the cell number in normal adult mice, suggesting that TGF- $\beta$ inhibition could improve neurogenesis (Pineda et al., 2013). However, the effect of TGF- $\beta$ on neurogenesis is still controversial. TGF- $\beta$ overexpression could enhance neurogenesis following gene transfection while depletion of TGF- $\beta$ receptor could also decrease neurogenesis and stem cell migration (Mathieu et al., 2010; He et al., 2014). Since activated Tregs were able to secret low level of TGF- $\beta$ and it might promote neurogenesis, we therefore neutralized TGF- $\beta$ to explore if it blocked NSC proliferation mediated by activated Tregs. Our results demonstrated that TGF- $\beta$ was not involved in activated Tregs-mediated NSC proliferation.

On the basis of cell morphology, ultrastructure, and molecular markers, NSCs in the SVZ were divided into four cell types (Doetsch et al., 1997; Riquelme et al., 2008): type A, proliferating neuroblasts; type B, slowly proliferating cells; type C, actively proliferative cells and type E, ependymal cells. Type B cells renew themselves and become type $\mathrm{C}$ and A cells (Gonzales-Roybal and Lim, 2013). Different cell types could be distinguished using different molecular markers (Ming and Song, 2005; Kirik and Korzhevskii, 2013): type A cells expressed DCX, PSANCAM, Tuj1 and $\mathrm{Hu}$; type B cells expressed GFAP; type C cells expressed Mash1; and type E cells expressed Vimentin. We used DCX, GFAP, Mash1 and Vimentin staining and showed 
that activated Tregs injection increased $\mathrm{BrdU}^{+} / \mathrm{Mash}^{+}$cells in naive mice, suggesting that Type $C$ cells were the major target. However, in the MCAO mice, activated Tregs increased $\mathrm{BrdU}^{+} / \mathrm{Mash}^{+}$cells and decreased $\mathrm{BrdU}^{+} / \mathrm{GFAP}^{+}$cells. This difference between normal and ischemic mice could be due to different microenvironment. Moreover, blocking IL-10 abolished the effect of activated Tregs on type B and C cell proliferation.

In summary, we showed that activated Tregs promoted NSC proliferation in ipsilateral SVZ of normal and ischemic mouse brains and blocking IL-10 abolished activated Tregs-mediated NSC proliferation, suggesting that the activated Treg/IL-10 pathway plays a critical role in neurogenesis in the SVZ after focal ischemia which may provide a new therapeutic approach for ischemic stroke.

\section{Author Contributions}

JW contributed to experimental design, cell culture, qRT-PCR, animal model making, immunostaining, data analyzing and

\section{References}

Barrat, F. J., Cua, D. J., Boonstra, A., Richards, D. F., Crain, C., Savelkoul, H. F., et al. (2002). In vitro generation of interleukin 10-producing regulatory CD4(+) $\mathrm{T}$ cells is induced by immunosuppressive drugs and inhibited by $\mathrm{T}$ helper type 1 (Th1)- and Th2-inducing cytokines. J. Exp. Med. 195, 603-616. doi: 10. 1084/jem.20011629

Becker, K. J. (2010). Modulation of the postischemic immune response to improve stroke outcome. Stroke 41, S75-S78. doi: 10.1161/STROKEAHA.110.592881

Brait, V. H., Arumugam, T. V., Drummond, G. R., and Sobey, C. G. (2012). Importance of $\mathrm{T}$ lymphocytes in brain injury, immunodeficiency and recovery after cerebral ischemia. J. Cereb. Blood. Flow Metab. 32, 598-611. doi: 10. 1038/jcbfm.2012.6

Brea, D., Agulla, J., Rodríguez-Yáñez, M., Barral, D., Ramos-Cabrer, P., Campos, F., et al. (2014). Regulatory T cells modulate inflammation and reduce infarct volume in experimental brain ischaemia. J. Cell. Mol. Med. 18, 1571-1579. doi: $10.1111 /$ jcmm.12304

Buckwalter, M. S., Yamane, M., Coleman, B. S., Ormerod, B. K., Chin, J. T., Palmer, T., et al. (2006). Chronically increased transforming growth factorbetal strongly inhibits hippocampal neurogenesis in aged mice. Am. J. Pathol. 169, 154-164. doi: 10.2353/ajpath.2006.051272

Casari, A., Schiavone, M., Facchinello, N., Vettori, A., Meyer, D., Tiso, N., et al. (2014). A Smad3 transgenic reporter reveals TGF-beta control of zebrafish spinal cord development. Dev. Biol. 396, 81-93. doi: 10.1016/j.ydbio.2014.09. 025

Chen, C., Lin, X. J., Wang, J. X., Tang, G. H., Mu, Z. H., Chen, X. Y., et al. (2014). Effect of HMGB1 on the paracrine action of EPC promotes postischemic neovascularization in mice. Stem Cells 32, 2679-2689. doi: 10. 1002/stem.1754

Chu, H. X., Kim, H. A. H., Lee, S., Moore, J. P., Chan, C. T., Vinh, A., et al. (2014). Immune cell infiltration in malignant middle cerebral artery infarction: comparison with transient cerebral ischemia. J. Cereb. Blood Flow Metab. 34, 450-459. doi: 10.1038/jcbfm.2013.217

Doetsch, F., Garcia-Verdugo, J. M., and Alvarez-Buylla, A. (1997). Cellular composition and three-dimensional organization of the subventricular germinal zone in the adult mammalian brain. J. Neurosci. 17, 5046-5061.

Ekdahl, C. T., Kokaia, Z., and Lindvall, O. (2009). Brain inflammation and adult neurogenesis: the dual role of microglia. Neuroscience 158, 1021-1029. doi: 10. 1016/j.neuroscience.2008.06.052

Gonzales-Roybal, G., and Lim, D. A. (2013). Chromatin-based epigenetics of adult subventricular zone neural stem cells. Front Genet. 4:194. doi: 10.3389/fgene. 2013.00194 drafting the article; LX contributed to design, cell culture, data analyzing and revising; $\mathrm{CY}, \mathrm{CR}, \mathrm{KZ}$ and $\mathrm{BW}$ contributed to part of immunostaining; $\mathrm{YW}$ and $\mathrm{ZZ}$ contributed to revising; KJ and GY-Y contributed to conception, design and revising.

\section{Funding}

This study was supported by research grants from US Public Health Service Grants (NS57186 KJ and AG21980 KJ), the National Natural Science Foundation of China (U1232205GYY and 81371305YTW), the Science and Technology Commission of Shanghai Municipality (13ZR1422600 ZJZ), and KC Wong Foundation (GY-Y).

\section{Acknowledgments}

We thank Chris McElroy, Yue Zhou and our colleagues at Med-X research center for the valuable comments on the manuscript.

Grossman, W. J., Verbsky, J. W., Barchet, W., Colonna, M., Atkinson, J. P., and Ley, T. J. (2004). Human T regulatory cells can use the perforin pathway to cause autologous target cell death. Immunity 21, 589-601. doi: 10.1016/j. immuni.2004.09.002

He, Y. B., Zhang, H., Yung, A., Villeda, S. A., Jaeger, P. A., Olayiwola, O., et al. (2014). ALK5-dependent TGF-beta signaling is a major determinant of latestage adult neurogenesis. Nat. Neurosci. 17, 943-952. doi: 10.1038/nn.3732

Hermann, D. M., Peruzzotti-Jametti, L., Schlechter, J., Bernstock, J. D., Doeppner, T. R., and Pluchino, S. (2014). Neural precursor cells in the ischemic brain integration, cellular crosstalk and consequences for stroke recovery. Front. Cell. Neurosci. 8:291. doi: 10.3389/fncel.2014.00291

Hori, S., Nomura, T., and Sakaguchi, S. (2003). Control of regulatory T cell development by the transcription factor Foxp3. Science 299, 1057-1061. doi: 10. $1126 /$ science. 1079490

Huang, G. J., Smith, A. L., Gray, D. H. D., Cosgrove, C., Singer, B. H., Edwards, A., et al. (2010). A genetic and functional relationship between $\mathrm{T}$ cells and cellular proliferation in the adult hippocampus. PLoS Biol. 8:e1000561. doi: 10 . 1371/journal.pbio.1000561

Jin, K., Sun, Y. J., Xie, L., Peel, A., Mao, X. O., Batteur, S., et al. (2003). Directed migration of neuronal precursors into the ischemic cerebral cortex and striatum. Mol. Cell. Neurosci. 24, 171-189. doi: 10.1016/s1044-7431(03)00159-3

Khattri, R., Cox, T., Yasayko, S. A., and Ramsdell, F. (2003). An essential role for Scurfin in CD4(+)CD25(+) T regulatory cells. Nat. Immunol. 4, 337-342. doi: 10.3410/f.1013067.188708

Kirik, O. V., and Korzhevskii, D. E. (2013). Vimentin in ependymal and subventricular proliferative zone cells of rat telencephalon. Bull. Exp. Biol. Med. 154, 553-557. doi: 10.1007/s10517-013-1998-3

Kiyota, T., Ingraham, K. L., Swan, R. J., Jacobsen, M. T., Andrews, S. J., and Ikezu, T. (2012). AAV serotype 2/1-mediated gene delivery of anti-inflammatory interleukin-10 enhances neurogenesis and cognitive function in APP+PS1 mice. Gene. Ther. 19, 724-733. doi: 10.1038/gt.2011.126

Kleinschnitz, C., Kraft, P., Dreykluft, A., Hagedorn, I., Göbel, K., Schuhmann, M. K., et al. (2013). Regulatory T cells are strong promoters of acute ischemic stroke in mice by inducing dysfunction of the cerebral microvasculature. Blood 121, 679-691. doi: 10.1182/blood-2012-04-426734

Kohman, R. A., and Rhodes, J. S. (2013). Neurogenesis, inflammation and behavior. Brain Behav. Immun. 27, 22-32. doi: 10.1016/j.bbi.2012.09.003

Kokaia, Z., Martino, G., Schwartz, M., and Lindvall, O. (2012). Cross-talk between neural stem cells and immune cells: the key to better brain repair? Nat. Neurosci. 15, 1078-1087. doi: 10.1038/nn.3163

Li, P. Y., Mao, L. L., Liu, X. R., Gan, Y., Zheng, J., Thomson, A. W., et al. (2014). Essential role of program death 1-ligand 1 in regulatory T-Cell-afforded 
protection against blood-brain barrier damage after stroke. Stroke 45, 857-864. doi: 10.1161/STROKEAHA.113.004100

Li, P. Y., Gan, Y., Sun, B. L., Zhang, F., Lu, B. F., Gao, Y. Q., et al. (2013a). Adoptive regulatory T-Cell therapy protects against cerebral ischemia. Ann. Neurol. 74, 458-471. doi: 10.1002/ana.23815

Li, P. Y., Mao, L. L., Zhou, G. Q., Leak, R. K., Sun, B. L., Chen, J., et al. (2013b). Adoptive regulatory $\mathrm{T}$-Cell therapy preserves systemic immune homeostasis after cerebral ischemia. Stroke 44, 3509-3515. doi: 10.1161/STROKEAHA.113. 002637

Liesz, A., Suri-Payer, E., Veltkamp, C., Doerr, H., Sommer, C., Rivest, S., et al. (2009). Regulatory T cells are key cerebroprotective immunomodulators in acute experimental stroke. Nat. Med. 15, 192-199. doi: 10.1038/nm.1927

Liston, A., and Gray, D. H. (2014). Homeostatic control of regulatory T cell diversity. Nat. Rev. Immunol. 14, 154-165. doi: 10.1038/nri3605

Liu, N., Chen, R. H., Du, H. W., Wang, J. H., Zhang, Y. X., and Wen, J. S. (2009). Expression of IL-10 and TNF-alpha in rats with cerebral infarction after transplantation with mesenchymal stem cells. Cell. Mol. Immunol. 6, 207-213. doi: $10.1038 / \mathrm{cmi} .2009 .28$

Mathieu, P., Piantanida, A. P., and Pitossi, F. (2010). Chronic expression of transforming growth factor-beta enhances adult neurogenesis. Neuroimmunomodulation 17, 200-201. doi: 10.1159/000258723

Ming, G. L., and Song, H. (2005). Adult neurogenesis in the mammalian central nervous system. Annu. Rev. Neurosci. 28, 223-250. doi: 10.1146/annurev.neuro. 28.051804.101459

Murray, P. J. (2006). Understanding and exploiting the endogenous interleukin10/STAT3-mediated anti-inflammatory response. Curr. Opin. Pharmacol. 6, 379-386. doi: 10.1016/j.coph.2006.01.010

Niebling, J., E Rünker, A., Schallenberg, S., Kretschmer, K., and Kempermann, G. (2014). Myelin-specific T helper 17 cells promote adult hippocampal neurogenesis through indirect mechanisms. F1000Res. 3:169. doi: 10. 12688/f1000research.4439.1

Ouyang, W. J., Rutz, S., Crellin, N. K., Valdez, P. A., and Hymowitz, S. G. (2011). Regulation and functions of the IL-10 family of cytokines in inflammation and disease. Annu. Rev. Immunol. 29, 71-109. doi: 10.1146/annurev-immunol031210-101312

Pereira, L., Font-Nieves, M., Van den Haute, C., Baekelandt, V., Planas, A. M., and Pozas, E. (2015). IL-10 regulates adult neurogenesis by modulating ERK and STAT3 activity. Front. Cell. Neurosci. 9:57. doi: 10.3389/fncel.2015.00057

Perez-Asensio, F. J., Perpiñá, U., Planas, A. M., and Pozas, E. (2013). Interleukin10 regulates progenitor differentiation and modulates neurogenesis in adult brain. J. Cell Sci. 126, 4208-4219. doi: 10.1242/jcs.127803

Pineda, J. R., Daynac, M., Chicheportiche, A., Cebrian-Silla, A., Sii Felice, K., Garcia-Verdugo, J. M., et al. (2013). Vascular-derived TGF-beta increases in the stem cell niche and perturbs neurogenesis during aging and following irradiation in the adult mouse brain. EMBO Mol. Med. 5, 548-562. doi: 10. 1002/emmm.201202197

Riquelme, P. A., Drapeau, E., and Doetsch, F. (2008). Brain micro-ecologies: neural stem cell niches in the adult mammalian brain. Philos. Trans. $R$ Soc. Lond. B Biol. Sci. 363, 123-137. doi: 10.1098/rstb.2006.2016

Ruan, L., Lau, B. W., Wang, J., Huang, L., Zhuge, Q., Wang, B., et al. (2014). Neurogenesis in neurological and psychiatric diseases and brain injury: from bench to bedside. Prog. Neurobiol. 115, 116-137. doi: 10.1016/j.pneurobio. 2013.12.006
Saino, O., Taguchi, A., Nakagomi, T., Nakano-Doi, A., Kashiwamura, S., Doe, N., et al. (2010). Immunodeficiency reduces neural stem/progenitor cell apoptosis and enhances neurogenesis in the cerebral cortex after stroke. J. Neurosci. Res. 88, 2385-2397. doi: 10.1002/jnr.22410

Saraiva, M., and O'Garra, A. (2010). The regulation of IL-10 production by immune cells. Nat. Rev. Immunol. 10, 170-181. doi: 10.1038/ nri2711

Schwartz, M., and Shechter, R. (2010). Protective autoimmunity functions by intracranial immunosurveillance to support the mind: the missing link between health and disease. Mol. Psychiatry 15, 342-354. doi: 10.1038/mp. 2010.31

Stubbe, T., Ebner, F., Richter, D., Engel, O. R., Klehmet, J., Royl, G., et al. (2013). Regulatory $\mathrm{T}$ cells accumulate and proliferate in the ischemic hemisphere for up to 30 days after MCAO. J. Cereb. Blood. Flow Metab. 33, 37-47. doi: 10. 1038/jcbfm.2012.128

Sun, J. H., Zheng, P. H., Wang, L. L., Li, J. J., Wang, J. Z., Wu, Q., et al. (2008). Survival and differentiation of neuroepithelial stem cells following transplantation into the lateral ventricle of rats. Chin. J. Physiol. 51, 247-251.

Tang, Y. H., Wang, J. X., Lin, X. J., Wang, L. Q., Shao, B., Jin, K. L., et al. (2014). Neural stem cell protects aged rat brain from ischemia-reperfusion injury through neurogenesis and angiogenesis. J. Cereb. Blood. Flow Metab. 34, 1138-1147. doi: 10.1038/jcbfm.2014.61

Tobin, M. K., Bonds, J. A., Minshall, R. D., Pelligrino, D. A., Testai, F. D., and Lazarov, O. (2014). Neurogenesis and inflammation after ischemic stroke: what is known and where we go from here. J. Cereb. Blood Flow Metab. 34, 1573-1584. doi: 10.1038/jcbfm.2014.130

Wang, B., and Jin, K. L. (2015). Current perspectives on the link between neuroinflammation and neurogenesis. Metab. Brain. Dis. 30, 355-365. doi: 10. 1007/s11011-014-9523-6

Wolf, S. A., Steiner, B., Akpinarli, A., Kammertoens, T., Nassenstein, C., Braun, A., et al. (2009). CD4-positive T lymphocytes provide a neuroimmunological link in the control of adult hippocampal neurogenesis. J. Immunol. 182, 3979-3984. doi: 10.4049/jimmunol.0801218

Yang, J. X., Jiang, Z. L., Fitzgerald, D. C., Ma, C. G., Yu, S., Li, H. M., et al. (2009) Adult neural stem cells expressing IL-10 confer potent immunomodulation and remyelination in experimental autoimmune encephalitis. J. Clin. Invest. 119, 3678-3691. doi: 10.1172/jci37914

Ziv, Y., Ron, N., Butovsky, O., Landa, G., Sudai, E., Greenberg, N., et al. (2006). Immune cells contribute to the maintenance of neurogenesis and spatial learning abilities in adulthood. Nat. Neurosci. 9, 268-275. doi: 10.3410/f. 1001179.360445

Conflict of Interest Statement: The authors declare that the research was conducted in the absence of any commercial or financial relationships that could be construed as a potential conflict of interest.

Copyright (c) 2015 Wang, Xie, Yang, Ren, Zhou, Wang, Zhang, Wang, Jin and Yang. This is an open-access article distributed under the terms of the Creative Commons Attribution License (CC BY). The use, distribution and reproduction in other forums is permitted, provided the original author(s) or licensor are credited and that the original publication in this journal is cited, in accordance with accepted academic practice. No use, distribution or reproduction is permitted which does not comply with these terms. 